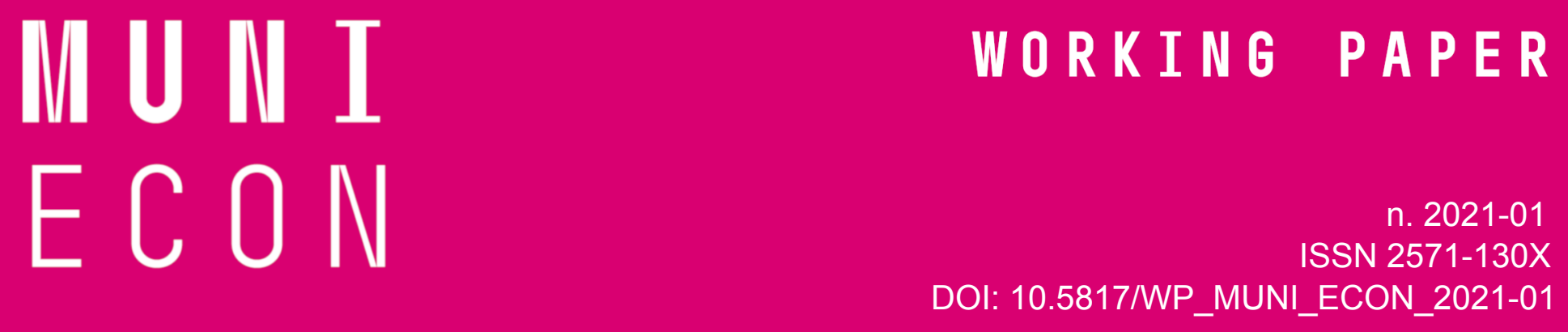

Published in: Economics of Transportation, 2021, Article

\title{
Can time-inconsistent preferences explain hypothetical biases?
}




\section{Can time-inconsistent preferences explain hypothetical biases?}

\section{Abstract}

We investigate whether the value of time (VOT) depends on when the corresponding preferences are measured: in advance, just before, or after the time period for which the time preferences are being evaluated. We find that the VOT is highest when elicited just before the time period. This is an indication of the VOT being affected by time-inconsistent, and more specifically, present-biased preferences. We argue that this result may explain why time valuations based on stated preference (SP) data are typically found to be lower than those based on revealed preference (RP) data: most RP surveys evaluate the preferences of respondents close to the time period for which the preferences are being measured, whereas the time instances for which preferences are evaluated in SP surveys tend to be more abstract, or referencing past or future time periods.

Masaryk University

Faculty of Economics and Administration

Authors:

Ondřej Krčál (ORCID: 0000-0002-8575-1203) / Masaryk University

Stefanie Peer (ORCID: 0000-0002-6106-8741) / Vienna University of Economics and Business

Rostislav Staněk (ORCID: 0000-0002-6310-4777) / Masaryk University

Contact: ondrej.krcal@econ.muni.cz

Creation date: $2021-01$

Revision date: 2023-01

Keywords: valuation of time, time inconsistency, present bias, hypothetical bias, lab experiment JEL classification: C91, D90

Citation:

Krčál, O., Peer, S., Staněk, R. (2021). Can time-inconsistent preferences explain hypothetical biases?. MUNI ECON Working Paper n. 2021-01. Brno: Masaryk University. https://doi.org/10.5817/WP_MUNI_ECON_2021-01 


\title{
Can time-inconsistent preferences explain hypothetical biases?
}

\author{
Ondřej Krčál ${ }^{\mathrm{a}, *}$, Stefanie Peer ${ }^{\mathrm{a}, \mathrm{b}}$, Rostislav Staněk ${ }^{\mathrm{a}}$ \\ ${ }^{a}$ Department of Economics, Masaryk University, Lipová 41a, 602 00 Brno, Czech Republic \\ ${ }^{b}$ Department of Socioeconomics, Vienna University of Economics and Business, Welthandelsplatz 1, 1020 Vienna, \\ Austria
}

\begin{abstract}
We investigate whether the value of time (VOT) depends on when the corresponding preferences are measured: in advance, just before, or after the time period for which the time preferences are being evaluated. We find that the VOT is highest when elicited just before the time period. This is an indication of the VOT being affected by time-inconsistent, and more specifically, present-biased preferences. We argue that this result may explain why time valuations based on stated preference (SP) data are typically found to be lower than those based on revealed preference (RP) data: most RP surveys evaluate the preferences of respondents close to the time period for which the preferences are being measured, whereas the time instances for which preferences are evaluated in SP surveys tend to be more abstract, or referencing past or future time periods.
\end{abstract}

Keywords: valuation of time, time inconsistency, present bias, hypothetical bias, lab experiment

\footnotetext{
${ }^{*}$ Corresponding author

Email addresses: ondrej.krcal@econ.muni.cz (Ondřej Krčál), stefanie.peer@wu.ac.at (Stefanie Peer), rostanek@mail.muni.cz (Rostislav Staněk)
} 


\section{Introduction}

Preferences are defined as time-consistent when the relative value of utility between two different time instances does not depend on when the corresponding preferences are evaluated (e.g. Cohen et al., 2020). The concept of 'time inconsistency' goes back to the seminal research of Strotz (1955), who was the first to realize that for any discount function other than the exponential function a person's preferences are time-inconsistent. Since then, economists have discovered timeinconsistent preferences in many different contexts, including financial decision making, health, and effort provision.

Many of these studies find evidence that individuals tend to make choices that their long-run selves regret such as the grabbing immediate rewards while avoiding immediate costs (O'Donoghue and Rabin, 1999). Such preference structures that (in trade-offs between two future time instances) attach a higher relative weight to the earlier instance the closer it gets, are usually referred to as present-biased (see overview by O'Donoghue and Rabin (2015)). Present-biased preferences can be explained by various psychological models, such as an over-pursuit of immediate gratification (e.g. Gul and Pesendorfer, 2001), impulsive choice (e.g. O'Donoghue and Rabin, 1999), optimistic beliefs (e.g. Breig et al., 2019), and (opportunity) costs of time being more salient in the present (e.g. Fischer, 2001). All these psychological models are in line with present time being deemed more valuable than future time. Some are also consistent with the notion that present time is deemed more valuable than past time (e.g., salience of opportunity costs of time).

As already suggested by Brownstone and Small (2005), time inconsistency may also explain the frequently found divergence between valuations based on stated preference (SP) and revealed preference (RP) data, which is usually attributed to the hypothetical character of SP surveys, and hence often referred to as "hypothetical bias". ${ }^{1}$ As an illustration, they use the example of individuals ending up taking toll lanes in real life due to running late, while in a hypothetical scenario they would opt for the standard (non-toll) lane. In turn, this causes the SP-based VOT to be lower than the corresponding RP-based VOT, as the lower propensity to pay for the toll in the SP setting translates in a higher cost coefficient, which drives down the corresponding value of time. The frequent finding that SP estimates tend to be lower than RP estimates (e.g. Ghosh, 2001; Hensher, 2001; Brownstone and Small, 2005; Small et al., 2005; Isacsson, 2007) is thus consistent with the existence of present-biased preferences.

In this paper, we estimate the willingness to accept a past, an imminent, and a future waiting time in a lab setup, where the underlying choice between receiving a monetary incentive and facing waiting time can be purely hypothetical or have real-life consequences. This setup allows us to draw conclusions on whether the valuations depend on the timing of the measurement (relative to when the waiting occurs), and if they depend on whether the underlying choice is incentivized (i.e. it has real consequences) or purely hypothetical. The only possibility to derive the valuations in the same way in advance, just before, and after the waiting time is to do so based on hypothetical questions, as the elicitation of the past waiting time cannot be incentivized. We therefore use the incentivized valuations mainly to test the validity of our hypothetical measures. We elicit the value of (waiting) time using multiple price lists. All valuations are in terms of willingness to accept,

\footnotetext{
${ }^{1}$ It is typically easier and cheaper to elicit the VOT from stated preference surveys. Moreover, SP surveys allow for testing non-existent alternatives, reducing correlations between attributes, and having full information on the available alternatives and attribute values. But these advantages come at a main disadvantage: the presence of hypothetical biases, which seem to exist even in very controlled lab settings, in which the only difference between the SP and the RP setting is whether a choice has real-life consequences or not (Krčál et al., 2019).
} 
and the real-life waiting time that is traded against money in the incentivized setting is part of a pre-scheduled lab session, such that individuals choosing against waiting can leave the lab session earlier than anticipated.

Consistent with Krčál et al. (2019), who employ a lab setting similar to the one used for this paper and show that the main driver of hypothetical biases are scheduling constraints (which tend to be ignored in the hypothetical setting), we do not find any differences between the hypothetical and incentivized valuation of time. We therefore conclude that our hypothetical valuations are unbiased. We find support for the time-inconsistency hypothesis of Brownstone and Small (2005). Participants of our experiment value present (waiting) time significantly higher than future and past (waiting) time. The ratio between the value of waiting time elicited 2 weeks in advance and just before the wait is about $2 / 3$, while the ratio between the value elicited 2 weeks after and just before the wait is about $4 / 5$. These results thus reflect time-inconsistent and, more specifically, present-biased preferences.

Our findings have potentially important implications for hypothetical biases in the value of time elicitation. They provide an indication that one reason why we usually observe RP-based valuations of time exceeding SP-based valuations may be because RP experiments/surveys usually concern time periods (e.g., trips) that are close in time to the experiment/survey, whereas SP experiments/surveys often refer to more abstract and/or distant time periods. More specifically, SP experiments often have an abstract, general framing that does not refer to a specific time instance, or, on the contrary, a very specific framing citing a reference point (e.g. Batley et al., 2019). The latter approach, which usually involves attribute values being pivoted around the reference trip, has become increasingly popular due to its feature of rendering the choice situations more realistic and potentially less prone to hypothetical bias (e.g. Hensher, 2010). Due to the specificity of the reference situation (for instance, in terms of mode choice, trip duration, or trip purpose), the most recent occurrence of the reference situation (e.g., a trip with specific characteristics) may have taken place some time ago, leading to a significant time gap between the trip and the measurement of the preferences that correspond to that trip. Exceptions to this are SP studies that only use reference trips that take place on the same day as the SP survey (Börjesson and Eliasson, 2014), or that recruit participants during a trip which is then used as reference trip (Kouwenhoven et al., 2014).

The paper contributes to the large body of literature on time valuation in transport. Most studies rely on SP data, with the potential presence of hypothetical biases being a major downside to the use of this data source. Time inconsistency has been suggested as an explanation for hypothetical biases, but so far little research has been conducted. One exception is Peer et al. (2014), who do not find evidence for time inconsistency, but this might be due to other confounding factors that drive their SP and RP estimates apart. Our results question the common use of retrospective reference points in SP surveys, and hence add to the recently emerging criticism of their usage: Hultkrantz and Savsin (2018) found that adding a reference point does not reduce the hypothetical bias; Peer and Börjesson (2018) show that reference points may not be stable, and the derived preferences may thus not correspond to long-term stable preferences required for welfare analysis; similarly, Hess et al. (2020) argue that reference points may induce short-run re-scheduling and loss-aversion.

We also contribute to the literature on time (in)consistency. Our approach of measuring time preferences, which is based on individuals' willingness to trade money against time spent on undesirable tasks (here: waiting), is consistent with the state-of-the-art of eliciting time preferences 
(Carvalho et al., 2016; Augenblick et al., 2015; Kölle and Wenner, 2018; Augenblick and Rabin, 2018). Unlike most of these studies that elicit the value of real effort we measure the value of (waiting) time. While existing studies typically analyze the value of real effort at two different moments in time, we keep the moment of waiting constant, and vary the timing of the elicitation. As a result, we reduce potentially confounding effects, in particular related to respondents' time constraints varying over time.

Our result that participants are less willing to wait now than they state they would be in two weeks are qualitatively similar to existing research on time-inconsistent preferences. For instance, Augenblick and Rabin (2018) find that participants want to complete $86 \%$ fewer tasks when the tasks are imminent versus when they are one week away. Furthermore, in a similar study as ours, Hultkrantz and Savsin (2018) find that the (SP-based) value of time is lower when an imprecise future situation ("later") is referred to rather than the "here and now". Compared to our paper, however, they adopt a more narrow experimental design: they only elicit an RP value for the "here and now" situation, and rely on the SP value for the "later" scenario. Moreover, they do not elicit the valuation ahead of the waiting time (to be spent on completing a task), and the waiting time amounts to only 15 minutes, as compared to 60 minutes in our study.

Unlike experiments that aim at eliciting time preferences, contingent valuation experiments on items other than time usually find that incentivized valuations are lower than hypothetical valuations (see for instance the meta-analyses by List and Gallet (2001); Little et al. (2004); Murphy et al. (2005a); Penn and $\mathrm{Hu}$ (2018)). This difference may be driven by the fact that unlike other items, time cannot be saved, and consumed in the future. Additional time can only be consumed on the spot, making it most valuable in present time. This may shed light on why hypothetical biases in time valuation often have a different sign than valuations of other items. The paper therefore also contributes to developing a more general theory on the presence of hypothetical biases, the necessity of which has been emphasized by Murphy et al. (2005b), Mitani and Flores (2010), and Loomis (2011).

The paper is structured as follows. Section 2 provides information on the experimental design. Section 3 gives an overview of the data including descriptive statistics. Section 4 shows the results of the regression models, and Section 5 concludes.

\section{Experimental design}

\subsection{Overview}

In this experiment, we are primarily interested in whether the value of (waiting) time depends on when it is elicited relative to the waiting time slot. We ask the participants of our lab experiment how much money they are willing accept for waiting one hour at a specific time and day. We use multiple price lists (MPLs) for this purpose. All participants were recruited among university students.

The monetary value attached to waiting time is elicited at three different moments in time with respect to the waiting time slot: two weeks before the waiting (before), just before the waiting (now), and two weeks after the waiting (after). When measured before the waiting (as in the before and now treatments), the value is elicited both in a setting where choices only have hypothetical consequences ( $H$ treatments) and in a setting where they have real consequences (incentivized $(I)$ treatments). In the latter setting, respondents may actually have to wait for an hour, but in return will receive a monetary payment. The incentivized VOT elicitation is not possible for the after 
treatment; we can only ask retrospectively in hypothetical terms, in return for how much money they would have been willing to wait for an hour at a specific time in the past.

In total, we thus have five treatments: before, now, and after hypothetical (before- $H$, now- $H$, and after- $H$ ) and before and now incentivized (before- $I$ and now- $I$ ). We will refer to the before, now, and after treatments as time treatments. The treatments $I$ and $H$ will be called incentive treatments. Each experimental subject participated in one treatment only (between-subject design). Figure 1 presents the position of the treatments within the experiment, which will be described in detail in the following sections.

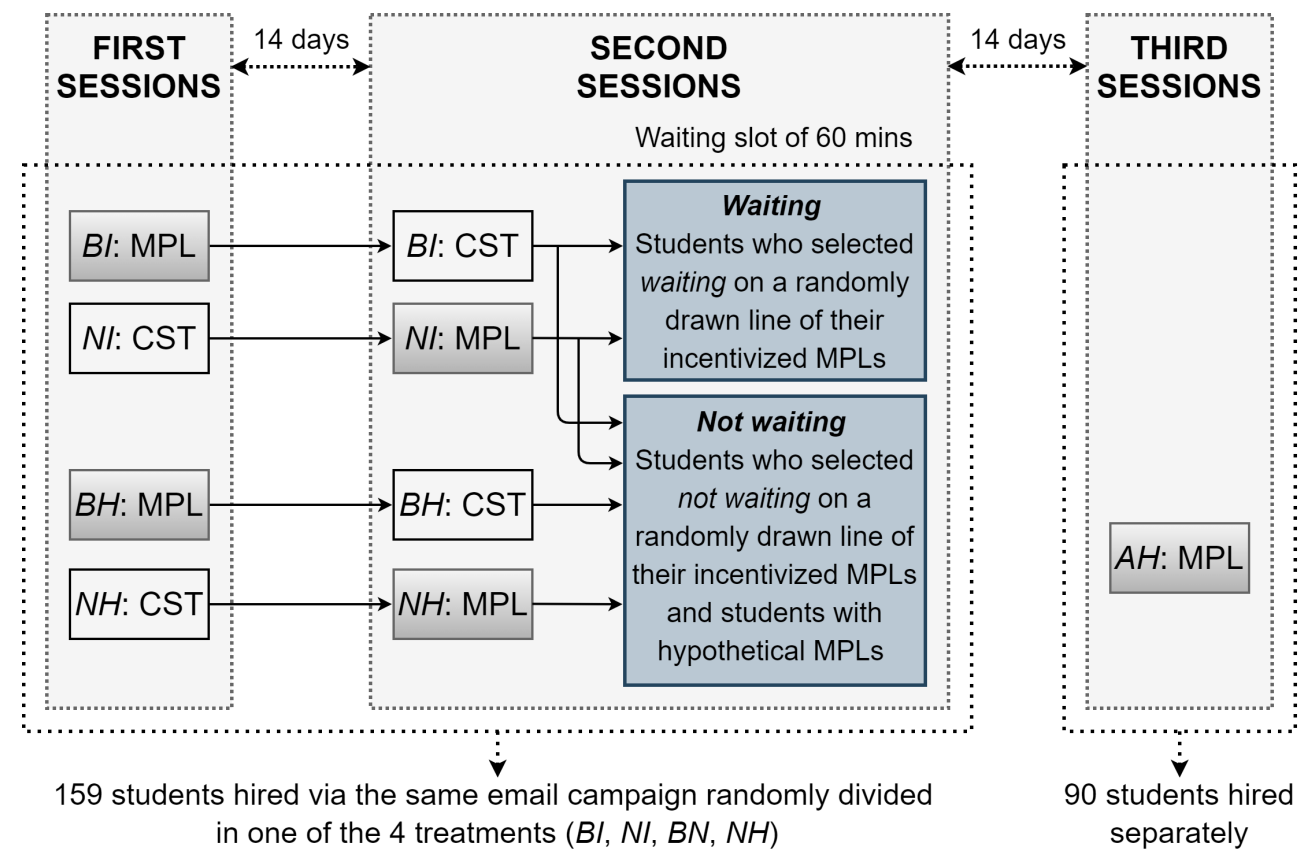

Figure 1

Overview of the experiment showing the timeline with the relative position of the first, second and third sessions, and outlining the hiring and waiting procedures. The upper part of the figure depicts the incentivized treatments before- $I$ and now- $I$ (BI and $N I$ ); the lower part the hypothetical treatments before- $H$, now- $H$, and after- $H$ (BH, NH, and $A H)$. Multiple price lists (MPLs) are used for value of time elicitation. The coding speed test (CST), performed in a parallel time slots with MPLs in the first and second sessions, measures cognitive abilities. The solid arrows depict how students proceed through the first and second sessions. The waiting/not-waiting boxes represent the time slot to which all the valuations in MPLs refer to.

\subsection{Value of time elicitation}

Both in the hypothetical $(H)$ as well as the incentivized $(I)$ treatments, we use multiple price lists (MPLs) to elicit the value assigned to avoiding the 1-hour waiting time. It contains choices between two options: 1) going home around one hour before the scheduled end of the experiment, and receiving no additional payment, and 2) waiting for 60 minutes, i.e. going home around the scheduled end of the experiment, and receiving a monetary compensation for the waiting time. The MPL consisted of 20 questions with the compensation for waiting ascending from 0 to almost 
209 CZK per hour. ${ }^{2}$ The structure of the MPL used in the experiment is presented in Table $1 .^{3}$ We recorded the midpoint between the values where the subject switches from not waiting to waiting for a given waiting time. The value thus corresponds to the monetary amount that the respondent requests in exchange for accepting an expected waiting time of one hour (willingness to accept (WTA)). If the subjects were not willing to wait even for 209 CZK (i.e., no switching value), we asked them to state their minimum WTA value instead.

Table 1

Structure of the multiple price list used in the experiment

\begin{tabular}{|c|c|c|c|c|}
\hline Waiting time & $\begin{array}{l}\text { Option A } \\
0 \text { minutes }\end{array}$ & & $\begin{array}{l}\text { or } \\
\text { or }\end{array}$ & $\begin{array}{c}\text { Option B } \\
60 \text { minutes } \\
\text { You can read Magazín M } \\
\text { while waiting. }\end{array}$ \\
\hline$[1]$ & you receive $0 \mathrm{CZK}$ & ० & or & you receive $0 \mathrm{CZK}$ \\
\hline$[2]$ & you receive $0 \mathrm{CZK}$ & $\circ$ & or & you receive $11 \mathrm{CZK}$ \\
\hline$[3]$ & you receive $0 \mathrm{CZK}$ & $\circ$ & or & you receive $22 \mathrm{CZK}$ \\
\hline$[4]$ & you receive $0 \mathrm{CZK}$ & $\circ$ & or & you receive $33 \mathrm{CZK}$ \\
\hline$\vdots$ & $\vdots$ & $\cdot$ & : & $\vdots$ \\
\hline$[17]$ & you receive $0 \mathrm{CZK}$ & $\circ$ & or & you receive $176 \mathrm{CZK}$ \\
\hline [18] & you receive $0 \mathrm{CZK}$ & $\circ$ & or & you receive $187 \mathrm{CZK}$ \\
\hline [19] & you receive $0 \mathrm{CZK}$ & $\circ$ & or & you receive $198 \mathrm{CZK}$ \\
\hline$[20]$ & you receive $0 \mathrm{CZK}$ & $\circ$ & or & you receive $209 \mathrm{CZK}$ \\
\hline
\end{tabular}

\subsection{Time treatments}

Participants in the before and now treatments volunteered to take part in an experiment consisting of two sessions two weeks apart from each other, each starting at 18.00 with an announced duration of 120 minutes. Due to the late timing of the sessions, none of the participants (all university students) had another class to attend after the end of these sessions, and hence no one needed to wait for other classes to start. Participants in the before and now treatments also knew that full participation in both sessions is necessary for receiving the compensation for taking part in the experiment (independent of their choices in the MPLs).

Participants in the before and now treatments could sign up for pairs of two sessions with the first sessions taking place on October 15,21, 22 and 23, 2019, and the second sessions taking place two weeks later (October 29 and November 4, 5, and 6, 2019). Participants were randomly assigned to one of four treatments: before-H, before- $I$, now-H, and now-I. In the first sessions, subjects assigned to the before treatments filled out the multiple price list (MPL) measuring the value attached to avoiding the waiting time two weeks ahead of the (potential) waiting time.

\footnotetext{
${ }^{2}$ At the time of the experiment 209 CZK corresponded to roughly twice the hourly wage of unqualified student labor in the Czech Republic. We avoided presenting any round numbers that could form focal points.

${ }^{3}$ In the MPL, once the subject had decided to wait in exchange for a specific reward, the option to wait was selected in all subsequent lines of the same MPL. If a subject is willing to wait for a certain amount, it is plausible to assume that (s)he will be willing to wait for all higher amounts too. The switching point could be moved simply by clicking on the right-hand side of the MPL. This feature of the experimental environment was implemented to reduce the chance that subjects become frustrated by having to fill in all 20 questions, which, especially in the hypothetical sessions, could lead to low-effort strategies, such as random clicking. Another consequence of this feature is that it is not possible to make inconsistent choices, such as multiple switching points in one MPL.
} 
Subjects assigned to the now treatments meanwhile filled in a coding speed test (see Section 2.6). Note that an actual wait can only occur in the $I$ treatments when a respondent makes choices in the MPLs that imply a wait time (see Section 2.4 for a more detailed explanation).

The second sessions can be regarded as the reference sessions, where the (potential) waiting occurs for which the value of waiting is measured in all three time treatments. The one-hour waiting time was scheduled from around 19.00 to 20.00 and hence within the 120 min time slot that participants had reserved for the experiment. ${ }^{4}$ Subjects assigned to the now treatments filled in the MPL (just before the potential waiting time), whereas subjects in the before treatments were asked to meanwhile fill in a coding speed test (see Section 2.6). At the beginning of the waiting time, students received an old issue of a magazine which had been distributed freely around Masaryk University several weeks before the experiment, and which was the only form of entertainment that they could use during the waiting time (no laptops, phones, or other reading materials were allowed). The exact instructions can be found in Appendix Appendix A. Subjects who did not wait in the second sessions (either because they were assigned to $H$ treatments or because they made choices in favor of leaving early in the $I$ treatments) could leave around 19.00, i.e. one hour before the scheduled end of the experimental session with no additional payment.

In addition to the first two sets of sessions, we organized the third sessions another two weeks after the second set of sessions (November 12, 18, 19, and 20), all of which contained the after$H$ treatment, and hence no actual waiting. Each participant in the after- $H$ treatment thus only participated in one session. In their MPLs they retrospectively provided their preferences for hypothetically having to wait for an hour two weeks earlier.

\subsection{Incentive treatments}

The only difference between the incentive treatments is whether the choices taken in the MPL have real consequences $(I)$ or purely hypothetical ones $(H)$. In the $I$ treatments, students were informed that one of the 20 questions contained in the MPL will be randomly selected, and their answer to this question will be implemented. Hence, if the choice of a student in the selected question was to wait 0 minutes, in the second session (s)he was free to leave around 19.00, i.e. one hour before the scheduled end of the session. If, however, (s)he was willing to wait for 60 minutes in return for receiving, e.g., $108 \mathrm{CZK}$, (s)he was informed that (s)he would have to wait for 60 minutes in the lab (leave around the scheduled end of the experiment) and only then would receive the compensation of $108 \mathrm{CZK}$ for waiting. In the $H$ treatments, in contrast, participants were informed that their choices would not have any consequences, yet they were asked to provide accurate answers based on their actual plans. As in the non-waiting choice in $I$ treatments, they were able to leave the second lab session one hour before its scheduled end and did not receive any additional payment.

\subsection{Questionnaire}

Before filling in the MPLs, every participant had to answer several questions regarding the waiting time and the time after the experimental session. The following 4 questions were included in the now treatments. Reworded versions of these questions have also been included in the before and after treatments:

1. "How busy will you be after the end of today's experimental session?" ${ }^{5}$ Answer on a scale of

\footnotetext{
${ }^{4}$ Note that in a related paper by Krčál et al. (2019), the waiting took time after the scheduled end of the session and hence was unexpected.

${ }^{5}$ In the before and after treatments, we specified the date.
} 
1 to 5 , where 1 means "I will not be busy at all" and 5 means "I will be completely busy"." The resulting variable will be denoted as Busy.

2. "How useful would it be for you if today's experimental session ended one hour earlier, i.e. at 19.00 instead of 20.00? Answer on a scale of 1 to 5 , where 1 means "It would not be useful at all" and 5 means "It would be very useful"." The resulting variable is Useful.

3. "Have you read the 'Magazín M' you have in front of you? Yes/No"? We were interested in whether the content of the issue was known to students prior to the experiment. If so and given that the magazine was the only permitted form of entertainment during the wait, the waiting would be more boring, potentially driving up the WTA. We label the variable as Read $M$.

4. "If so, please estimate how many percent of articles have you read from this copy? 5 options: 0, 25, 50, 75, 100 percent." The corresponding variable is called Read Perc.

In the after- $H$ treatment, there were three additional questions at the beginning of the questionnaire: First, we asked them whether on the date 14 days ago they were in Brno (a dummy variable In Brno), whether they remembered what they were doing (a dummy variable Remember), and whether they could imagine that they would register for an experimental session lasting from 18.00 to 20.00 (a dummy variable Imagine).

\subsection{Coding speed test (CST)}

In order to keep the time of the parallel experimental sessions similar, participants who were assigned to a treatment that, for a given session, did not involve filling in an MPL completed a coding speed test (CST). In the CST, which measures the speed of information processing (Segal, 2012), participants had 5 minutes time to match as many words as possible with four-digit numbers according to a key. The key, visible during the entire task, contained 10 words and their respective codes. In each question, participants were asked to match a word with one of the five codes offered. The speed-coding test was incentivized: participants received a piece rate of $1 \mathrm{CZK}$ for each correct answer. As shown by Segal (2012), the scores in the incentivized test tend to reflect cognitive ability.

\subsection{Procedures}

Registration was carried out through hroot (Bock et al., 2014) by sending an e-mail to subjects registered in the hroot database. The invitation for the first and second sessions contained a common link through which individuals could select one of four pairs of dates. These students were randomly assigned to one of the four treatments (before- $H$, before- $I$, now- $H$, now- $I$ ) right before the start of their first experimental session. before and now treatments were conducted during the same time slots in two separate laboratories. In each lab, students were randomly divided into the $H$ and the $I$ treatment. Most of the instructions were read aloud, only those parts of instructions which differed between the $H$ and $I$ treatment were displayed on the screen, such that students were not aware of what the other parallel treatments were. A different e-mail was sent out for the after- $H$ treatment inviting students to register for one of the third sessions, each of them containing an MPL with purely hypothetical consequences.

We used a computerized experimental environment programmed in the Software $z$ Tree (Fischbacher, 2007). All sessions took between 100 and 120 minutes. The first 90 to 100 minutes of the first sessions were dedicated to tasks unrelated to the experiment presented in this paper. The last 10 to 20 minutes were spent either on the coding speed test or on filling out the questionnaire 
and the MPL. An experimenter read the instructions aloud with students following slides with examples of the experimental environment to be seen on the computer screens in front of them. ${ }^{6}$

In the second sessions (with potential waiting), the computerized experimental tasks ended for all students at the same moment (including MPLs for those assigned to now treatments and the coding speed test for those assigned to before treatments), namely around one hour before the pre-announced end of the session. The students who were not selected for waiting (all participants of $H$ treatments and some participants of $I$ treatments) were paid in private in a random order and were asked to leave the lab individually. ${ }^{7}$ The payment included all applicable payoffs from both weeks, including the payment for participating in the coding speed test. Participants selected for waiting sat in the lab during the payment procedure. Their waiting started as soon as half of the students were paid, so that on average they stayed for 60 minutes longer than their peers who were not waiting. No participants left before the end of the assigned waiting time.

\section{Data}

A total number of 249 students participated in the experiment. In the before and now treatments, 159 subjects participated in the first round of sessions and 153 in the second round of sessions. $^{8}$ This results in 157 filled MPLs $(I: 77 ; H: 82)$, and 153 full observations that include both MPLs and CST $(I: 75 ; H: 78)$. The remaining 90 subjects participated in third sessions in the after treatment.

Table 2 provides summary statistics of the data set. The first line shows the value of waiting time in CZK, which was elicited from the MPLs. The respondent-specific value of waiting time is calculated as the average of the lowest value for which a respondent indicated to be willing to wait for one hour and the value of the previous line of the MPL. No participants switched on the first line, i.e. no one was willing to wait for free. Only 8 subjects were not willing to wait even for the highest amount offered, i.e. $209 \mathrm{CZK}$ (0 in before, 7 in now, and 1 in after treatments). The WTA attributed to these MPLs is $214.5 \mathrm{CZK}$, which corresponds to the participants switching at another equidistant value of $220 \mathrm{CZK} .{ }^{9}$ The WTA is highest for the now treatments $(119 \mathrm{CZK})$; the WTA elicited from the before treatments is only about $2 / 3$ of that amount ( $82 \mathrm{CZK}$ ), and the WTA from the after treatment about 4/5 (94 CZK), respectively.

The second segment of the table shows descriptive statistics related to the questionnaire and the coding speed test. Participants expect to be more busy in the evening when asked on the same day (now) than when asked 14 days earlier or later (compared to before: $t=-4.84, p<0.001$; compared to after: $t=-2.66, p=0.009)$. Similarly, students would find it more useful if the

\footnotetext{
${ }^{6}$ For the experimental instructions, see Appendix A.

${ }^{7}$ The difference between the first and the last participant leaving the lab was roughly 10 minutes.

${ }^{8} 6$ students did not participate in the second round of sessions, and therefore did not receive any payment from this experiment. We made sure that there were no participants taking part in the first session who did not intend to participate in the second session. All students were informed several times that they would not receive any payoffs if they do not show up for the second session. Judging from the excuses we received by email, the no-shows were related to unexpected situations such as hospitalization or illness. We therefore use all the data collected in the first sessions.

${ }^{9}$ This assumption likely underestimates the mean value in now treatments. If we used the minimum WTA that these 8 participants filled in after failing to choose any switching value offered in their MPLs, the average WTA in now treatments would be $148 \mathrm{CZK}$ (after excluding one participant whose minimum WTA equalled 500,000 CZK) compared to $82 \mathrm{CZK}$ in before and $96 \mathrm{CZK}$ in after. In the rest of the paper, we use the conservative value of 214.5 CZK, since the alternative minimum WTA values seem quite unrealistic.
} 
experimental session ended one hour earlier in the treatment now than in before $(t=-2.41$, $p=0.02)$ or after $(t=-3.22, p=0.002)$. Surprisingly, students were much more likely to have read Magazin $M$ in the after treatments than in the before or now treatments (Fisher test $p=0.0008$ ). This difference is likely to be only due to chance or measurement error, not least because the estimated percentage of articles read (Read Perc) in after does not significantly exceed the percentage in the other two treatments $(t=-1.55, p=0.12)$.

The following lines show that among those assigned to the after treatment, $94 \%$ were in Brno two weeks ago (In Brno), $90 \%$ remember what they did on the evening when the experimental session would have taken place (Remember), and $62 \%$ can imagine that they would have registered for the session two weeks ago (Imagine). The coding-speed-test scores are similar in before and now treatments.

The third segment of the table shows descriptive statistics regarding socioeconomic variables. Participants tend to be fairly young (which is to be expected given students as subject pool). Our sample includes fewer women than men, and consists of roughly equal numbers of Czech and Slovak students, respectively. Slightly above half of the participants study economics. None of the socioeconomic variables differs significantly between the three time treatments.

Table 2

Summary statistics

\begin{tabular}{|c|c|c|c|c|c|c|}
\hline Statistic & $\mathrm{N}$ & $\begin{array}{l}\text { Before } \\
\text { Mean (SD) }\end{array}$ & $\mathrm{N}$ & $\begin{array}{l}\text { Now } \\
\text { Mean (SD) }\end{array}$ & $\mathrm{N}$ & $\begin{array}{l}\text { After } \\
\text { Mean (SD) }\end{array}$ \\
\hline WTA (CZK) & 81 & $81.69(45.48)$ & 76 & $119.12(56.82)$ & 90 & $93.62(52.37)$ \\
\hline Busy & 81 & $2.73(1.16)$ & 76 & $3.66(1.24)$ & 90 & $3.12(1.36)$ \\
\hline Useful & 81 & $3.20(1.08)$ & 76 & $3.66(1.30)$ & 90 & $3.01(1.28)$ \\
\hline Read M & 81 & $0.05(0.22)$ & 76 & $0.08(0.27)$ & 90 & $0.21(0.41)$ \\
\hline Read Perc & 81 & $3.42(13.26)$ & 76 & $3.30(15.20)$ & 90 & $6.44(15.46)$ \\
\hline In Brno & - & - & - & - & 90 & $0.94(0.23)$ \\
\hline Remember & - & - & - & - & 90 & $0.90(0.30)$ \\
\hline Imagine & - & - & - & - & 90 & $0.62(0.49)$ \\
\hline CST & 77 & $53.61(11.29)$ & 76 & $54.97(11.28)$ & - & - \\
\hline Age & 81 & $21.67(2.14)$ & 76 & $21.37(2.27)$ & 90 & $21.66(1.90)$ \\
\hline Female & 81 & $0.41(0.49)$ & 76 & $0.47(0.50)$ & 90 & $0.48(0.50)$ \\
\hline Czech & 81 & $0.46(0.50)$ & 76 & $0.53(0.50)$ & 90 & $0.50(0.50)$ \\
\hline Econ & 81 & $0.58(0.50)$ & 76 & $0.59(0.50)$ & 90 & $0.48(0.50)$ \\
\hline
\end{tabular}

\section{Results}

Figure 2 presents the mean willingness to accept (WTA) in all five treatments of the experiment. We use hypothetical elicitation because the valuation in the after treatment cannot be incentivized. We included the incentivized before and now treatments to test the validity of our hypothetical measures. Consistently with the results of a similar experimental study by Krčál et al. (2019), we find that incentives have no statistically significant impact on the WTA $(t=0.16, p=0.87$ in the before and $t=-0.56, p=0.57$ in the now treatments), so we expect our hypothetical measure to be precise also in the after treatment. Timing, on the other hand, affects the WTA significantly. After pooling the incentivized and hypothetical data in the before and now treatments, the value of waiting in the now treatments is significantly higher than in the before treatments $(t=4.54$, 
$p<0.0001)$ and in the after treatment $(t=2.99, p=0.003)$. The difference between the before and after treatments is not statistically significant $(t=-1.60, p=0.11)$.

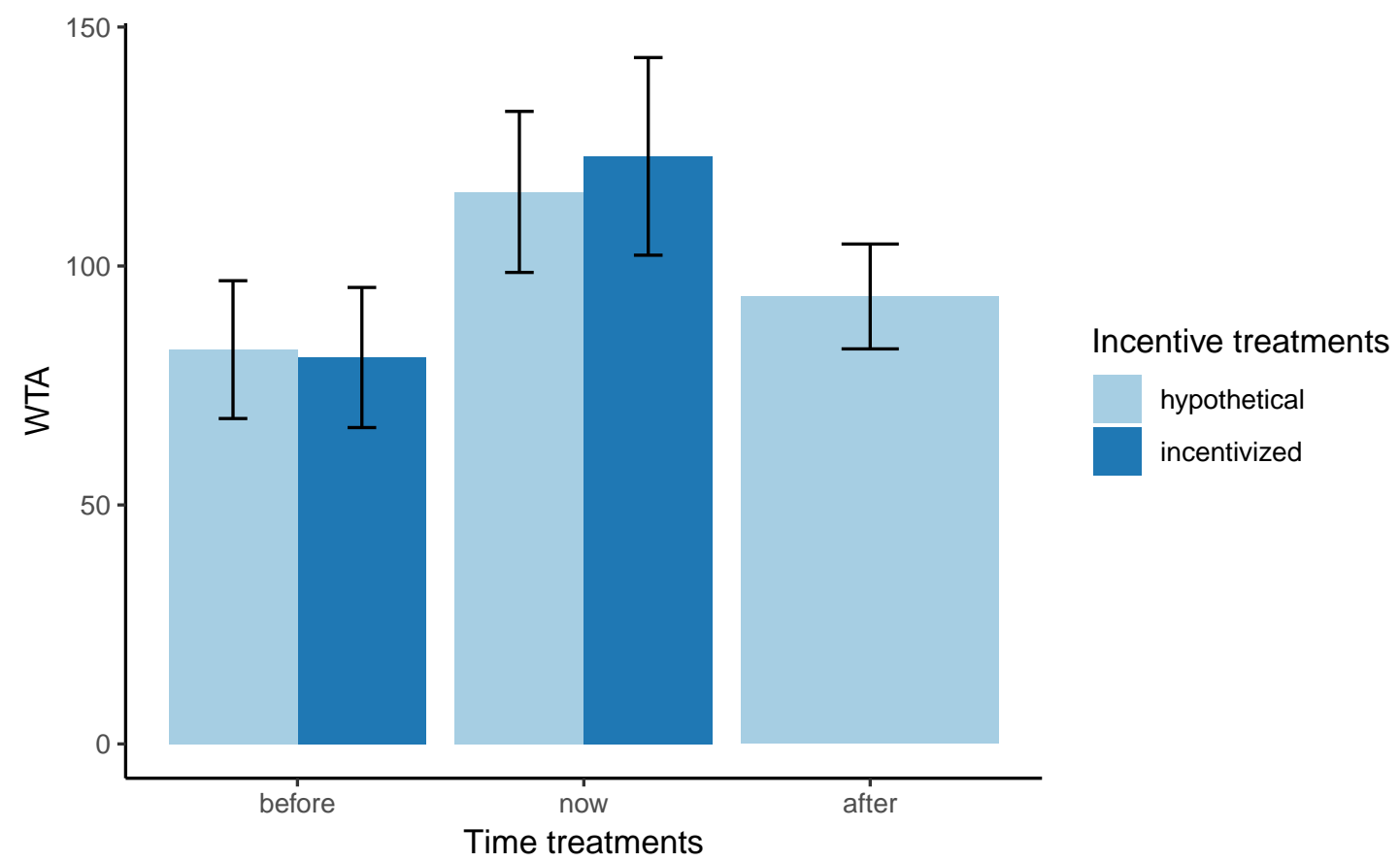

Figure 2

WTA elicited at the moment of waiting (now), 2 weeks before the waiting (before), and 2 weeks after (after), separately for the incentivized and the hypothetical treatment. The bars show the $95 \%$ confidence intervals.

The regression analyses presented in Table 3 confirm the findings of Figure 2. Models 1 and 2 show that the WTA elicited two weeks before the waiting (before) is about two thirds of the WTA elicited minutes before the waiting (now), and the difference is highly statistically significant. Compared to the now treatments, the WTA two weeks after the waiting (after) drops by about $20 \%$ and the difference is again statistically significant. The effect sizes and significance hold also when adding controls for the incentive treatments (Hypothetical) in Model 2 and for other subject-specific variables in Model 3.

Models 4 and 5 add controls for the perceived value of the waiting time. Useful measures the perceived usefulness of the time during the waiting slot; Busy indicates how busy the participants are expected to be after the end of the experimental session that contained the waiting slot. Both variables are measured on a Likert scale from 1 to 5 . As shown in Table 2, participants regard their time as more valuable on the day of the (potential) waiting time compared to when asked about the same time instance two weeks earlier or two weeks after. Models 4 and 5 show that while the perceived usefulness increases the WTA, having a busy evening after the experiment has no significant impact. The parameters of before and after decrease slightly, but they remain economically important and statistically significant, although after only at the $10 \%$ level. This result suggests that the time treatment effects are driven by other factors than the perceived usefulness of time on the waiting day. 
Table 3

OLS regressions of WTA for waiting in expected time

\begin{tabular}{|c|c|c|c|c|c|}
\hline \multirow[t]{2}{*}{ Dep. var.: } & \multicolumn{5}{|c|}{ WTA (CZK) } \\
\hline & (1) & (2) & (3) & (4) & (5) \\
\hline Constant & $\begin{array}{c}119.118^{* * *} \\
(5.928)\end{array}$ & $\begin{array}{c}120.527^{* * *} \\
(7.298)\end{array}$ & $\begin{array}{c}130.059^{* * *} \\
(36.945)\end{array}$ & $\begin{array}{l}93.776^{* *} \\
(38.165)\end{array}$ & $\begin{array}{l}79.238^{* *} \\
(40.066)\end{array}$ \\
\hline Before & $\begin{array}{c}-37.433^{* * *} \\
(8.253)\end{array}$ & $\begin{array}{c}-37.452^{* * *} \\
(8.268)\end{array}$ & $\begin{array}{c}-38.025^{* * *} \\
(8.353)\end{array}$ & $\begin{array}{c}-34.367^{* * *} \\
(8.293)\end{array}$ & $\begin{array}{c}-31.845^{* * *} \\
(8.556)\end{array}$ \\
\hline After & $\begin{array}{c}-25.496^{* * *} \\
(8.051)\end{array}$ & $\begin{array}{c}-24.160^{* * *} \\
(9.013)\end{array}$ & $\begin{array}{c}-22.661^{* *} \\
(9.184)\end{array}$ & $\begin{array}{c}-17.004^{*} \\
(9.209)\end{array}$ & $\begin{array}{c}-16.224^{*} \\
(9.225)\end{array}$ \\
\hline Hypothetical & & $\begin{array}{l}-2.745 \\
(8.265)\end{array}$ & $\begin{array}{l}-3.627 \\
(8.381)\end{array}$ & $\begin{array}{l}-4.794 \\
(8.244)\end{array}$ & $\begin{array}{l}-4.244 \\
(8.250)\end{array}$ \\
\hline Useful & & & & $\begin{array}{c}8.286^{* * *} \\
(2.691)\end{array}$ & $\begin{array}{l}7.180^{* *} \\
(2.847)\end{array}$ \\
\hline Busy & & & & & $\begin{array}{c}3.300 \\
(2.791)\end{array}$ \\
\hline Female & & & $\begin{array}{c}-11.583^{*} \\
(6.825)\end{array}$ & $\begin{array}{c}-12.083^{*} \\
(6.708)\end{array}$ & $\begin{array}{c}-11.595^{*} \\
(6.715)\end{array}$ \\
\hline Econ & & & $\begin{array}{l}-1.943 \\
(7.024)\end{array}$ & $\begin{array}{l}-2.284 \\
(6.903)\end{array}$ & $\begin{array}{l}-1.251 \\
(6.952)\end{array}$ \\
\hline Age & & & $\begin{array}{l}-0.127 \\
(1.639)\end{array}$ & $\begin{array}{c}0.230 \\
(1.615)\end{array}$ & $\begin{array}{c}0.484 \\
(1.628)\end{array}$ \\
\hline Czech & & & $\begin{array}{c}2.661 \\
(6.683)\end{array}$ & $\begin{array}{c}1.544 \\
(6.577)\end{array}$ & $\begin{array}{c}1.373 \\
(6.573)\end{array}$ \\
\hline Read M & & & $\begin{array}{c}-1.193 \\
(15.896)\end{array}$ & $\begin{array}{c}1.043 \\
(15.636)\end{array}$ & $\begin{array}{c}1.171 \\
(15.623)\end{array}$ \\
\hline Read Perc & & & $\begin{array}{l}-0.312 \\
(0.341) \\
\end{array}$ & $\begin{array}{l}-0.374 \\
(0.335) \\
\end{array}$ & $\begin{array}{l}-0.365 \\
(0.335)\end{array}$ \\
\hline Observations & 247 & 247 & 247 & 247 & 247 \\
\hline $\mathrm{R}^{2}$ & 0.081 & 0.081 & 0.098 & 0.133 & 0.138 \\
\hline Adjusted $\mathrm{R}^{2}$ & 0.073 & 0.070 & 0.064 & 0.096 & 0.098 \\
\hline
\end{tabular}

Note: Standard errors in parentheses. Significance: ${ }^{*} p<0.1 ;{ }^{* *} p<0.05 ;{ }^{* * *} p<0.01$. 
Krčál et al. (2019) link hypothetical biases (i.e. differences between incentivized and hypothetical treatments) in the value of unexpected waiting time to participants' score in the coding speed test (CST). In this study, we do not find any significant differences between the incentivized and hypothetical values, presumably because the waiting takes place in the time scheduled for the experimental sessions, and so the valuation decision is not complicated enough for the coding speed test to matter. It is therefore unlikely that the CST scores correlate with the WTA in our data. Table 4 displays results based only on data from the treatments before and now. It adds normalized CST scores (CSTNorm) into the regressions presented in Table 3. As expected, it shows that the value of waiting time is neither affected by the CST scores alone, nor in interaction with the incentive treatment (Hypothetical $\times$ CSTNorm).

Table 4

OLS regressions of WTA for waiting in expected time - only treatments before and now

\begin{tabular}{|c|c|c|c|c|c|}
\hline \multirow[t]{2}{*}{ Dep. var.: } & \multicolumn{5}{|c|}{ WTA (CZK) } \\
\hline & (1) & $(2)$ & (3) & (4) & (5) \\
\hline Constant & $\begin{array}{c}119.118^{* * *} \\
(5.946)\end{array}$ & $\begin{array}{c}114.323^{* * *} \\
(29.839)\end{array}$ & $\begin{array}{c}129.713^{* *} \\
(54.370)\end{array}$ & $\begin{array}{c}82.076 \\
(56.944)\end{array}$ & $\begin{array}{c}63.323 \\
(58.737)\end{array}$ \\
\hline Before & $\begin{array}{c}-38.476^{* * *} \\
(8.382)\end{array}$ & $\begin{array}{c}-38.340^{* * *} \\
(8.500)\end{array}$ & $\begin{array}{c}-38.825^{* * *} \\
(8.590)\end{array}$ & $\begin{aligned}-34.644^{* * *} & (8.620)\end{aligned}$ & $\begin{array}{c}-30.830^{* * *} \\
(9.118)\end{array}$ \\
\hline Hypothetical & & $\begin{array}{c}-2.395 \\
(39.049)\end{array}$ & $\begin{array}{c}1.590 \\
(39.703)\end{array}$ & $\begin{array}{c}6.824 \\
(39.095)\end{array}$ & $\begin{array}{c}10.333 \\
(39.113)\end{array}$ \\
\hline CSTNorm & & $\begin{array}{c}0.125 \\
(0.598)\end{array}$ & $\begin{array}{c}0.376 \\
(0.614)\end{array}$ & $\begin{array}{c}0.446 \\
(0.605)\end{array}$ & $\begin{array}{l}0.456 \\
(0.604)\end{array}$ \\
\hline $\begin{array}{l}\text { Hypothetical } \\
\times \text { CSTNorm }\end{array}$ & & $\begin{array}{l}-0.010 \\
(0.774)\end{array}$ & $\begin{array}{l}-0.139 \\
(0.787)\end{array}$ & $\begin{array}{l}-0.264 \\
(0.775)\end{array}$ & $\begin{array}{l}-0.318 \\
(0.775)\end{array}$ \\
\hline Useful & & & & $\begin{array}{l}8.760^{* *} \\
(3.608)\end{array}$ & $\begin{array}{l}6.676^{*} \\
(3.961)\end{array}$ \\
\hline Busy & & & & & $\begin{array}{c}4.951 \\
(3.925)\end{array}$ \\
\hline Female & & & $\begin{array}{c}-16.290^{*} \\
(8.845)\end{array}$ & $\begin{array}{c}-17.041^{*} \\
(8.702)\end{array}$ & $\begin{array}{c}-16.151^{*} \\
(8.713)\end{array}$ \\
\hline Econ & & & $\begin{array}{c}-15.844^{*} \\
(9.327)\end{array}$ & $\begin{array}{c}-15.127 \\
(9.175)\end{array}$ & $\begin{array}{c}-13.911 \\
(9.207)\end{array}$ \\
\hline Age & & & $\begin{array}{l}-0.610 \\
(2.009)\end{array}$ & $\begin{array}{l}-0.004 \\
(1.991)\end{array}$ & $\begin{array}{c}0.280 \\
(1.999)\end{array}$ \\
\hline Czech & & & $\begin{array}{c}5.305 \\
(8.650)\end{array}$ & $\begin{array}{c}5.171 \\
(8.505)\end{array}$ & $\begin{array}{c}5.370 \\
(8.489)\end{array}$ \\
\hline Read M & & & $\begin{array}{c}14.179 \\
(23.799)\end{array}$ & $\begin{array}{c}16.652 \\
(23.421)\end{array}$ & $\begin{array}{c}17.994 \\
(23.396)\end{array}$ \\
\hline Read Perc & & & $\begin{array}{l}-0.094 \\
(0.406)\end{array}$ & $\begin{array}{l}-0.226 \\
(0.403)\end{array}$ & $\begin{array}{l}-0.237 \\
(0.402)\end{array}$ \\
\hline Observations & 153 & 153 & 153 & 153 & 153 \\
\hline $\mathrm{R}^{2}$ & 0.122 & 0.124 & 0.160 & 0.194 & 0.203 \\
\hline Adjusted $\mathrm{R}^{2}$ & 0.117 & 0.100 & 0.101 & 0.131 & 0.134 \\
\hline
\end{tabular}

Note: Standard errors in parentheses. Significance: ${ }^{*} p<0.1 ;{ }^{* *} p<0.05 ;{ }^{* * *} p<0.01$. 


\section{Conclusions}

Our results show that individuals have a significantly higher willingness-to-accept (WTA) waiting time when the WTA is elicited just before the waiting time (now), as compared to when the elicitation takes place two weeks before (before) or after the waiting time (after). Our results thus indicate time-inconsistent and, more specifically, present-biased time preferences.

Our finding of present-biased preferences is in line with the literature (Carvalho et al., 2016; Augenblick et al., 2015; Kölle and Wenner, 2018; Augenblick and Rabin, 2018). Various explanations for present-biased preferences have been brought forward and may also apply to our case, even though we are not able to empirically identify the contribution of each in explaining our results:

1. Salience of opportunity costs: In the now treatment, opportunity costs of time are likely to be more salient than in the before and after treatments, rendering the WTA higher in the former case, and lower in the two latter cases. Or in the words of Fischer (2001, p. 250): "Opportunity costs of time today are more salient than those tomorrow; that is, today's opportunities are clear while tomorrow's are vague, making the former seem more pressing." This explanation is in line with our finding that participants consider it more useful for the experimental session to end one hour early in the now treatments compared to the before and after treatments.

2. Immediate gratification: Respondents might find it tempting to leave the class before its scheduled end in the now treatments, driven by the thought of immediate gratification (Gul and Pesendorfer, 2001), which is absent in the before and after treatments. Closely related, they may act impulsively in the now treatments, over-weighting the imminent reward (i.e., leaving early), in line with the "human tendency to grab immediate rewards and to avoid immediate costs in a way that our "long-run selves" do not appreciate" (O'Donoghue and Rabin, 1999, p. 103). Such imminent rewards are absent in the before and after treatments, but also in the hypothetical $(H)$ treatments.

3. Optimistic beliefs: Respondents may have overly optimistic beliefs about their time availability in the future (and possibly also in the past). This explanation is again in line with participants stating that ending the experimental session one hour early would be more useful for them in the now treatments than in the before and after treatments, and that they consider themselves more busy in the evening after the now treatments compared to the other two treatments.

Our finding that hypothetical and incentivized valuations do not differ is consistent with a related paper by Krčál et al. (2019). They show that for the case where the only difference between the $H$ and the $I$ treatments is whether the consequences of the choices are real, differences in the valuations between these two treatments are mainly due to scheduling constraints: they are taken into account in the $I$ treatments but to a much lesser extent in the $H$ treatments. This is especially the case for persons who do not perform well in the coding speed test (CST), which is an indication of low cognitive ability. Since scheduling constraints are absent in the experiment presented here (as the waiting takes place within a pre-scheduled session), our results of hypothetical biases being absent and CST scores having no explanatory power are in line with the results obtained by Krčál et al. (2019). Thanks to this, our hypothetical measures of the VOT are likely to be unbiased even in the after treatment, in which an incentivized measure is not available.

The results of our paper may provide a possible explanation for why SP- and RP-based valuations may diverge. In many papers that compare SP- and RP-based estimates of time valuations, 
the timing of when time preferences are measured relative to the time to which they apply seems to on average differ between SP- and RP-based choices. More specifically, RP data are usually elicited close to the time to which they apply (e.g., just before, during, or after a trip for which the time preferences are of interest). Moreover, almost always relate to a specific time instance (e.g., a specific trip). SP data, in contrast, are often more abstract in terms of which time they refer to (e.g., often referring to a general, unidentified trip, and leaving the exact timing of the trip open), or, on the contrary, refer to a specific time in the past (e.g., a so-called reference trip, around which the attribute values are pivoted). As such reference trips are often required to have certain properties, for instance, in terms of mode choice, duration, or trip purpose, it is quite likely that the reference trip has not taken place very close to the time of the elicitation, and might thus resemble more closely our after treatment rather than our now treatments. Our results regarding the presence of present-biased preferences might thus explain why SP-based valuations are often found to be lower than RP-based ones, as the former are more likely to correspond to the before or after treatments, whereas the latter are more likely to correspond to the now treatments.

For the design of SP surveys with the purpose to measure time valuations for trips, our results suggest that, in order to decrease the hypothetical bias, they should be framed such that they refer to a specific, current trip rather than remaining ambiguous or referring to specific trips in the past. In light of this, trying to recruit respondents for an SP survey just before or during a trip, which then is the reference trip, seems to be sensible approach (similar to Kouwenhoven et al. (2014)). Also limiting reference trips to trips that have taken place on the same day as the SP survey (Börjesson and Eliasson, 2014) may be useful; however, based on the research conducted here, we cannot be sure how close the timing of the elicitation and the timing of the trip (or waiting time) need to be in order to eliminate any difference in the valuations arising from the different time treatments. As individuals tend to not be aware of their present bias (Augenblick and Rabin, 2018), it might also help to tell respondents about the potential occurrence of time inconsistencies before they fill in the SP survey, a concept often referred to as "cheap talk" and frequently employed in the contingent valuation literature (e.g. Loomis, 2014; Murphy et al., 2005a).

A possible limitation of the research conducted here is that the value of waiting time has only been elicited just before the wait, two weeks before, and two weeks after. We chose the twoweek time periods for several reasons. First, the two-week time period was attractive because participants are likely to not yet have a fully formed schedule for the later date. This situation resembles reference trips that have taken place a longer time ago as well as vague SP scenarios. Second, we anticipated that an invitation to an experiment consisting of several sessions within a single week would only be appealing to students with a lot of available time, such that our participants would not be representative of our subject pool, which could decrease the external validity of our results. Finally, the available capacity of the computer labs could not accommodate all first-round sessions during one week. As we wanted to make sure that all first-round sessions were completed before the sessions that included the actual waiting started (in order to avoid potential contamination across sessions), the first and the second round of sessions were scheduled two weeks apart. As a result, we do not know how the preferences develop within the two weeks before and after the waiting. However, some indication that little change may occur above a short time difference is provided by Balakrishnan et al. (2020) who show that present bias affects choices only if the consequences are immediate compared to even a delay of a few hours. In terms of interpreting the time difference between the two rounds of sessions as the time difference between a reference trip (as often used in SP surveys) and the measurement of the corresponding time 
preferences, we can argue that two weeks is realistic for a reference trip that is fairly specific and infrequent. Given the results of Balakrishnan et al. (2020), we expect to find similar effects even if the SP survey is referenced to trips that are more common (e.g. commuting trips).

We have elicited the value of waiting time with a duration of 60 minutes, during which scheduling constraints were absent and participants were only allowed to read a student magazine. The waiting time thus resembled a situation in which the duration of the waiting is known in advance (no uncertainty), but in which access to mobile devices and other forms of entertainment is not feasible. Transferred to a transport context, this might represent a situation in which one is taking an (on-time) public transport connection with poor internet access. For future work, it would also be interesting to investigate different baselines, for instance, when waiting time can be spent in a more useful way than in the experiment presented here, when the waiting duration is shorter or longer than 60 minutes, and has an uncertain end time. This is to advance our understanding regarding the emergence of time-inconsistent preferences in time valuation.

In our experiments, the sample consisted of university students. While their absolute WTA is likely to be lower than the WTA we would have obtained from a representative sample (as students tend to have relatively low wages and low opportunity costs), we are confident that timeinconsistent preferences would also be found for the wider population. They might be even more prominent in a representative sample due to opportunity costs being higher and thus more salient. Nevertheless, it would still be interesting to repeat the research with a more diverse sample in terms of socioeconomic characteristics, and moreover, include additional question items and experiments that would allow us to better understand which psychological processes are most likely to drive our results.

\section{Acknowledgments}

We would like to thank Katarína Čellárová and Jana Zuzaňáková for excellent research assistance.

\section{Funding}

This article is the output of the project called "New Mobility - High-Speed Transport Systems and Transport-Related Human Behaviour", Reg. No. CZ.02.1.01/0.0/0.0/16_026/0008430, cofinanced by the "Operational Programme Research, Development and Education".

\section{References}

Augenblick, Ned and Matthew Rabin, "An experiment on time preference and misprediction in unpleasant tasks," Review of Economic Studies, 2018, 86 (3), 941-975.

_ , Muriel Niederle, and Charles Sprenger, "Working over time: Dynamic inconsistency in real effort tasks," The Quarterly Journal of Economics, 2015, 130 (3), 1067-1115.

Balakrishnan, Uttara, Johannes Haushofer, and Pamela Jakiela, "How soon is now? Evidence of present bias from convex time budget experiments," Experimental Economics, 2020, 23 (2), 294-321.

Batley, Richard, John Bates, Michiel Bliemer, Maria Börjesson, Jeremy Bourdon, Manuel Ojeda Cabral, Phani Kumar Chintakayala, Charisma Choudhury, Andrew Daly, Thijs Dekker et al., "New appraisal values of travel time saving and reliability in Great Britain," Transportation, 2019, 46 (3), 583-621.

Bock, Olaf, Ingmar Baetge, and Andreas Nicklisch, "hroot: Hamburg registration and organization online tool," European Economic Review, 2014, 71, 117-120. 
Börjesson, Maria and Jonas Eliasson, "Experiences from the Swedish Value of Time study," Transportation Research Part A: Policy and Practice, 2014, 59, 144-158.

Breig, Zachary, Matthew Gibson, and Jeffrey Shrader, "Why do we procrastinate? Present bias and optimism," Present Bias and Optimism (February 15, 2019), 2019.

Brownstone, David and Kenneth A. Small, "Valuing time and reliability: assessing the evidence from road pricing demonstrations," Transportation Research Part A: Policy and Practice, 2005, 39 (4), 279-293.

Carvalho, Leandro S, Stephan Meier, and Stephanie W Wang, "Poverty and economic decision-making: Evidence from changes in financial resources at payday," American Economic Review, 2016, 106 (2), 260-84.

Cohen, Jonathan, Keith Marzilli Ericson, David Laibson, and John Myles White, "Measuring time preferences," Journal of Economic Literature, 2020, 58 (2), 299-347.

Fischbacher, Urs, "z-Tree: Zurich toolbox for ready-made economic experiments," Experimental Economics, 2007, $10(2), 171-178$.

Fischer, Carolyn, "Read this paper later: Procrastination with time-consistent preferences," Journal of Economic Behavior \& Organization, 2001, 46 (3), 249-269.

Ghosh, A., "Valuing time and reliability. Commuters' mode choice from a real time congestion pricing experiment." PhD dissertation, University of California at Irvine 2001.

Gul, Faruk and Wolfgang Pesendorfer, "Temptation and self-control," Econometrica, 2001, 69 (6), 1403-1435.

Hensher, David, "The valuation of commuter travel time savings for car drivers: evaluating alternative model specifications," Transportation, 2001, 28 (2), 101-118.

Hensher, David A., "Hypothetical bias, choice experiments and willingness to pay," Transportation Research Part B: Methodological, 2010, 44 (6), 735-752.

Hess, Stephane, Andrew Daly, and Maria Börjesson, "A critical appraisal of the use of simple time-money trade-offs for appraisal value of travel time measures," Transportation, 2020, pp. 1-30.

Hultkrantz, Lars and Selen Savsin, "Is 'referencing'a remedy to hypothetical bias in value of time elicitation? Evidence from economic experiments," Transportation, 2018, 45 (6), 1827-1847.

Isacsson, Gunnar, "The trade off between time and money: Is there a difference between real and hypothetical choices?," Swedish National Road and Transport Research Institute, Borlange, Sweden, 2007.

Kölle, Felix and Lukas Wenner, "Present-biased generosity: Time inconsistency across individual and social contexts," Technical Report, CeDEx Discussion Paper Series 2018.

Kouwenhoven, Marco, Gerard C. de Jong, Paul Koster, Vincent A.C. van den Berg, Erik T. Verhoef, John Bates, and Pim M.J. Warffemius, "New values of time and reliability in passenger transport in The Netherlands," Research in Transportation Economics, 2014, 47, 37-49.

Krčál, Ondřej, Stefanie Peer, Rostislav Staněk, and Bara Karlinova, "Real consequences matter: Why hypothetical biases in the valuation of time persist even in controlled lab experiments," Economics of Transportation, 2019, 20,100138 .

List, John A and Craig A Gallet, "What experimental protocol influence disparities between actual and hypothetical stated values?," Environmental and Resource Economics, 2001, 20 (3), 241-254.

Little, Joseph, Robert Berrens et al., "Explaining disparities between actual and hypothetical stated values: further investigation using meta-analysis," Economics Bulletin, 2004, 3 (6), 1-13.

Loomis, John, "What's to know about hypothetical bias in stated preference valuation studies?," Journal of Economic Surveys, 2011, 25 (2), 363-370.

Loomis, John B, "2013 WAEA keynote address: Strategies for overcoming hypothetical bias in stated preference surveys," Journal of Agricultural and Resource Economics, 2014, 39 (1), 34-46.

Mitani, Yohei and Nicholas E Flores, "Public goods referenda without perfectly correlated prices and quantities," in "Allied Social Sciences Meeting, Atlanta" 2010.

Murphy, James J, P Geoffrey Allen, Thomas H Stevens, and Darryl Weatherhead, "A meta-analysis of hypothetical bias in stated preference valuation," Environmental and Resource Economics, 2005, 30 (3), 313-325.

_ , Thomas Stevens, and Darryl Weatherhead, "Is cheap talk effective at eliminating hypothetical bias in a provision point mechanism?," Environmental and Resource Economics, 2005, 30 (3), 327-343.

O'Donoghue, Ted and Matthew Rabin, "Doing it now or later," American Economic Review, 1999, 89 (1), $103-124$.

_ and _ , "Present bias: Lessons learned and to be learned," American Economic Review, 2015, 105 (5), $273-79$.

Peer, Stefanie and Maria Börjesson, "Temporal framing of stated preference experiments: does it affect valuations?," Transportation Research Part A: Policy and Practice, 2018, 117, 319-333.

_ , Jasper Knockaert, Paul Koster, and Erik T Verhoef, “Over-reporting vs. overreacting: Commuters' perceptions of travel times," Transportation Research Part A: Policy and Practice, 2014, 69, 476-494.

Penn, Jerrod M and Wuyang Hu, "Understanding hypothetical bias: An enhanced meta-analysis," American Journal 
of Agricultural Economics, 2018, 100 (4), 1186-1206.

Segal, Carmit, "Working when no one is watching: Motivation, test scores, and economic success," Management Science, 2012, 58 (8), 1438-1457.

Small, Kenneth A, Clifford Winston, and Jia Yan, "Uncovering the distribution of motorists' preferences for travel time and reliability," Econometrica, 2005, 73 (4), 1367-1382.

Strotz, Robert Henry, "Myopia and inconsistency in dynamic utility maximization," The Review of Economic Studies, 1955, 23 (3), 165-180. 


\section{ONLINE APPENDIX}

\section{Appendix A. Experimental instructions [translated from Czech]}

\section{Appendix A.1. Waiting-treatment before}

I will explain the rules of the experiment first. From now on, please listen carefully. During the explanation, we will pause for questions several times. If you have a question, please raise your hand and one of the instructors will come to you to answer your question in private.

In this experiment, we will now ask you to imagine that you will wait here for 60 minutes during the experimental session in 14 days. ${ }^{10}$ The waiting would last roughly from 19.00 to 20.00. While waiting, you would sit at your desk in the lab. You could not use anything while waiting; the only thing you could do is reading Magazine M, which lies in front of you. You would not be allowed to talk to anyone at all times.

Is everything clear? Leave time for questions and answer in private.

In this experiment, you will have to decide if you want to go home right after the end of the experimental session in 14 days $^{11}$ roughly at 19.00 without receiving any additional amount of money from us, or if you would be willing to wait for 60 minutes and get some additional amount of money from us.

\section{Is everything clear? Leave time for questions and answer in private.}

Read the instructions yourself. If you are unsure, raise your hand at any time. We will come to you and answer your question in private.

[The following paragraph is shown on a screen only to incentivized treatments] If you opt for an option with a waiting time of 0 minutes, you will not receive any additional money from us. In 14 days $^{12}$, at around 19.00, we will pay you for all parts of the experiment, and you will be able to leave. If you decide on an option with a waiting time of 60 minutes, you will wait here in 14 days $^{13}$ from approximately 19 to 20 hours. After these 60 minutes, you will receive your payoff from all parts of the experiment, plus an additional amount of money for waiting. We will explain all the details below.

[The following paragraph is shown on a screen only to hypothetical treatments]

These questions will be hypothetical. In any case, you leave in 14 days at about 19.00, and you don't get any additional payment, just the payoffs of the other parts of the experiment. However, we ask you to imagine that the possibility of waiting could actually occur and respond accordingly. We will explain all the details below. ${ }^{14}$

\footnotetext{
${ }^{10}$ Instead of the text in italics in the treatment now: "In this experiment, we will now ask you to imagine that you will wait here for 60 minutes during today's experimental session" and in the treatment after: "Exactly 14 days ago, on [day, date], there was an experimental session in this lab. Imagine that you attended this session. When you signed up for this session, you were informed that this session would last from 18.00 to 20.00. So you expect the session to end at 20.00. Next, imagine that you might have waited here during the experimental session for 60 minutes."

${ }^{11}$ Instead of the text in italics in treatment now: "today" and in treatment after: "14 days ago"

${ }^{12}$ Instead of italics in treatment now: "Today"

${ }^{13}$ Instead of italics in treatment now: "today"

${ }^{14}$ Instead of italics in treatment now: "These questions will be hypothetical. In any case, you leave today at about 19.00, and you will not get any additional payment, just the payoffs of the other parts of the experiment. However,
} 
Is everything clear? Leave time for questions and answer in private.

The questionnaire consists of 20 questions. You will have to choose 20 times between an earlier departure without additional amount of money and waiting for an additional amount of money. We have prepared an example that will not be used in the experiment. The monetary amounts in the example are for illustrative purposes only. Let us go through this example together. (Show Figure A.3). We will ask you to choose one of the options in each row. This may look like this: In the first line, you decide if you prefer option A ["Možnost A" in Czech]: receive 0 CZK and wait for 0 minutes (the left box) or option B ["Možnost B"]: receive 0 CZK and wait 60 minutes (the right box). If you prefer to wait 0 minutes, which box should you select? (The answer should be left) Correct, you should click on the left box.

Is everything clear? Leave time for questions and answer in private.

In case you prefer option $\mathrm{B}$, receiving $0 \mathrm{CZK}$ and waiting for 60 minutes, then you should click on the right box. In the second line, you decide between the possibility of waiting 0 minutes for 0 CZK and waiting 60 minutes for 2 CZK. Please, note that the amount on the right side gradually increases line by line. As long as you prefer to wait 0 minutes, you click on the left box. When you prefer option $\mathrm{B}$, waiting 60 minutes, then you should click on the right box.

Is everything clear? Leave time for questions and answer in private.

Once you click on the box to the right, the right boxes in all the following lines are automatically filled out. (Show Figure A.4) For example, consider a situation where you prefer to wait 60 minutes for $10 \mathrm{CZK}$ to leaving the experiment without additional compensation for waiting. In this case, we assume that you prefer to wait for 30 minutes for $12 \mathrm{CZK}, 14 \mathrm{CZK}, 16 \mathrm{CZK}$, and all other higher amounts.

At the same time, all the left boxes are automatically filled out in the previous lines. If you answer questions line by line from the top and you first click right on the line with $10 \mathrm{CZK}$, it means that you prefer to wait 0 minutes for 0 CZK over waiting 60 minutes for $8 \mathrm{CZK}$. In that case, we also assume that you prefer not to wait at all over waiting 60 minutes for $6 \mathrm{CZK}, 4 \mathrm{CZK}$, and any of the other lower amounts shown in the previous lines. If you find that you want to change the lowest amount you are willing to wait for, just click on the right side of the questionnaire and your choice will be readjusted. Once you have completed the questionnaire, you can press the "Stop Decision Making" button. On the following screen, we will ask you an additional question. ${ }^{15}$

Is everything clear? Leave time for questions and answer in private.

Read the instructions yourself. If you are unsure, raise your hand at any time. We will come to you and answer your question in private.

[This paragraph is shown on a screen only to incentivized treatments, together with Figure A.5.] Now you will learn how you can earn money in this experiment. You will complete a questionnaire that contains 20 lines with 20 questions. At the end of the experiment, the computer randomly

we ask you to imagine that the possibility of waiting could actually occur and respond accordingly. We will explain all the details below.", and in treatment after: "However, we ask you to imagine that you attended a session at which the possibility of waiting could actually occur and respond accordingly. We will explain all the details below."

${ }^{15}$ The text in italics is shown only in the before treatment. The question on the following screen was as follows: "In the previous questionnaire, you indicated that in 14 days you are willing to wait in the lab from 19.00 to 20.00 for [their switching value] CZK and more. How likely will you be dissatisfied with your choice if in 14 days the computer randomly determines that you will wait here in return for receiving [the switching value] CZK? Answer on a scale of 1 to 10 , where 1 is "very unlikely," and 10 is "very likely." 


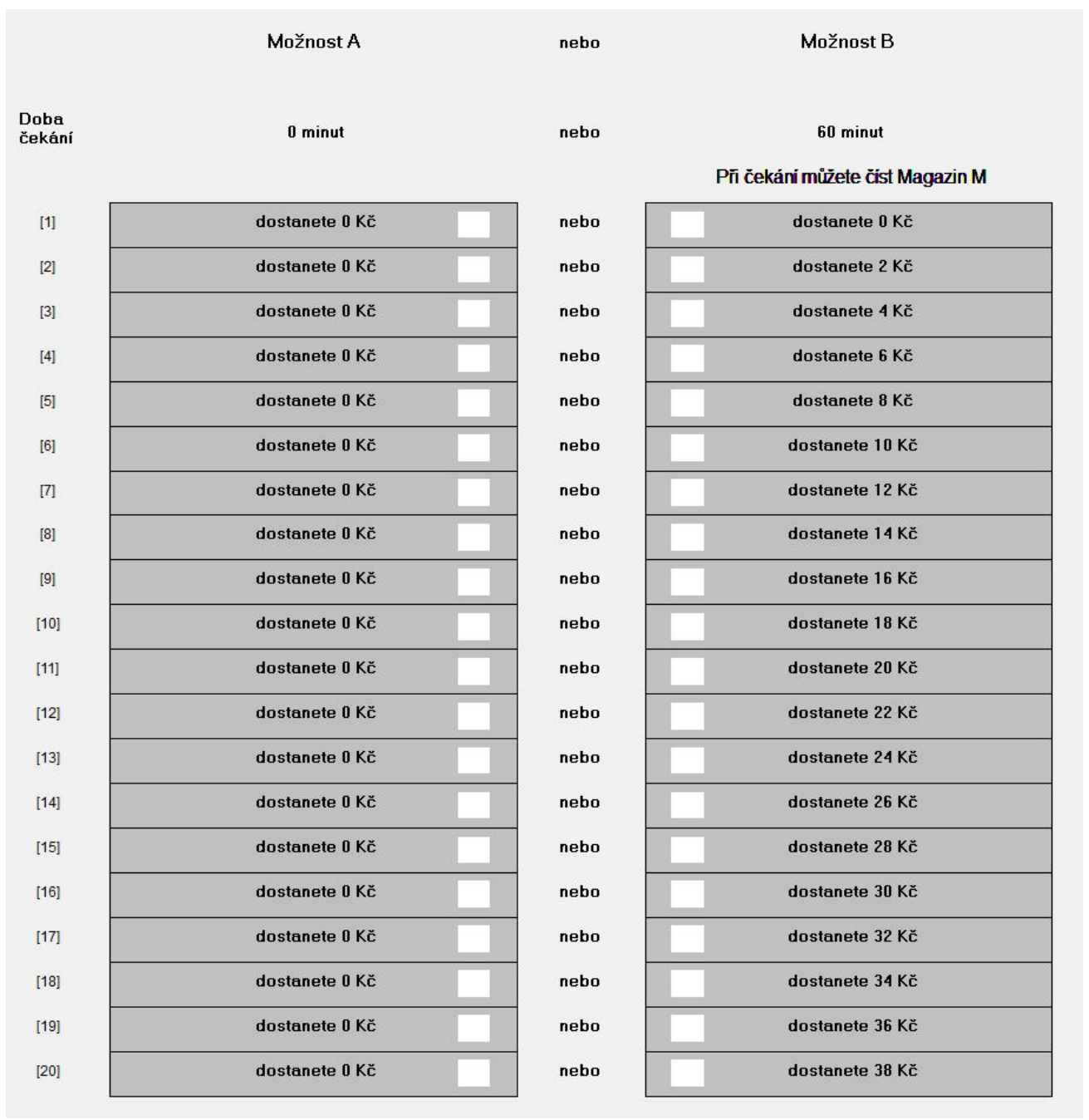

Figure A.3

Instructions - screen 1

selects one of the 20 rows. Suppose row 5 is selected. This is the most important part: If you had chosen the left box of the decision sheet, you will not wait and you will not receive any additional payment. If you had chosen the right side of our example, you would wait 60 minutes you could read Magazine $\mathrm{M}$ while waiting) and get $8 \mathrm{CZK}$.

[This paragraph is shown on a screen only to incentivized treatments, together with Figure A.6.] Consider another example. Suppose that instead of line 5, the computer randomly selects the line 16. What would happen if you had selected the left box? You will wait for 0 minutes and get 0 CZK. What would happen if you had selected the right box? You will wait 60 minutes and get 30 CZK. Since the selection of all 20 options is equally probable, you should consider each of your decisions in all individual rows because any row can be selected for payoff.

Before proceeding with the experiment, we ask you to complete a short questionnaire. If there are no other questions, we can move on to the questionnaire. Please answer truthfully. After you complete the questionnaire, we will begin the experiment. 


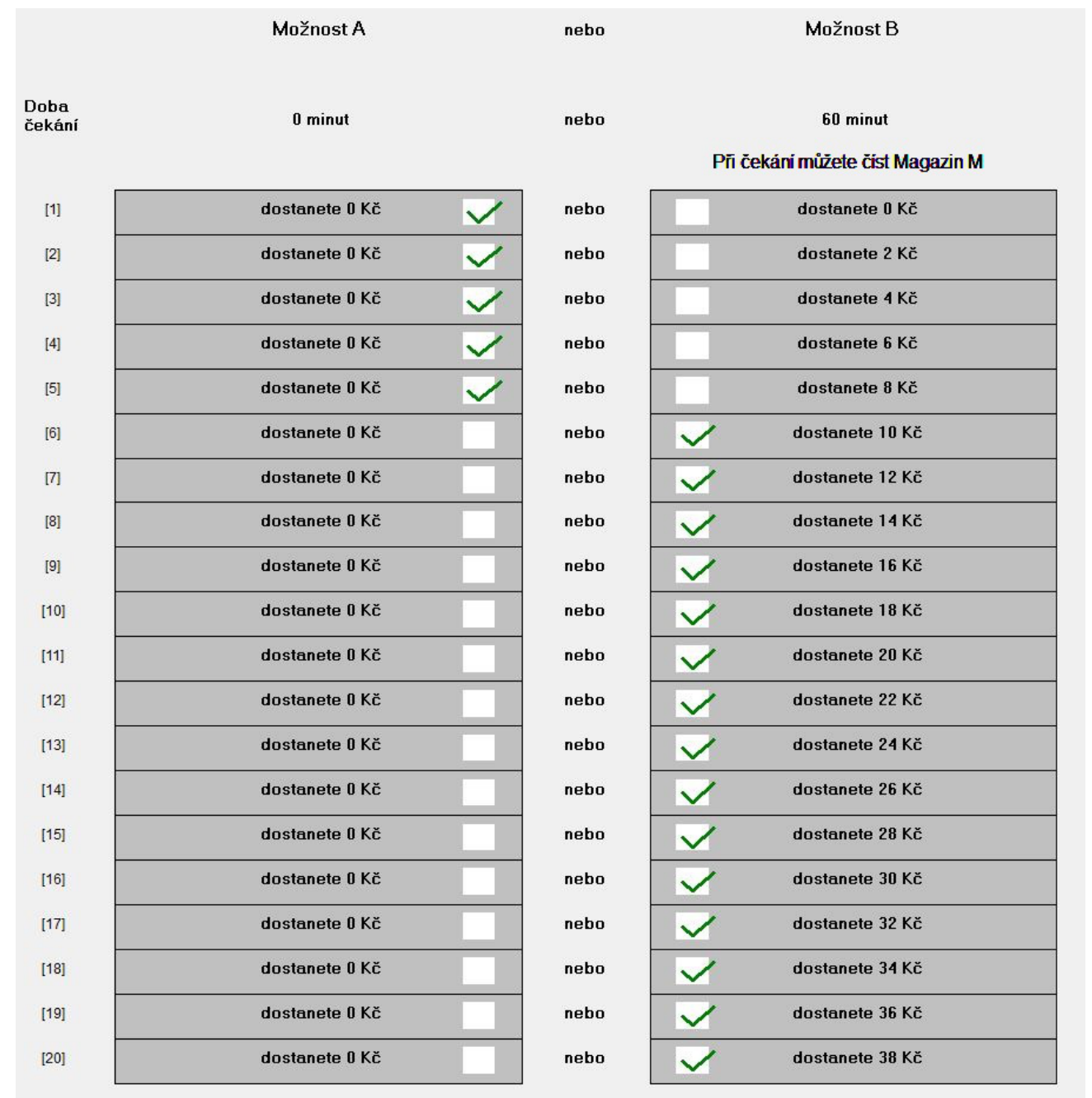

Figure A.4

Instructions - screen 2

Is everything clear? Leave time for questions and answer in private.

\section{Appendix A.2. Coding speed test}

From now on, please listen carefully. If you have a question, please raise your hand and one of the instructors will come to you to answer your question privately.

In this part of the experiment, we measure how quickly information can be processed. Now we will let you solve an example of this test that will not be used in the experiment (show Figure A.8).

You will find a "key" ["klíč" in Czech] in the test, which is a group of words and each word is assigned a four-digit number. You will see the key on the top left of the screen. Each question in the test is one word from that key. These questions can be found at the bottom left part of the screen. Your task is to select the number that belongs to the word from the options offered. You can choose the correct answer by selecting the appropriate circle for each question on the right side of your screen. 


\begin{tabular}{|c|c|c|c|}
\hline & Možnost A & nebo & Možnost B \\
\hline $\begin{array}{l}\text { Doba } \\
\text { čekání }\end{array}$ & 0 minut & nebo & 60 minut \\
\hline & & & Pĩ čekáni mi̊žete čist Magazin M \\
\hline [1] & dostanete 0 Kč & nebo & dostanete $0 \mathrm{Kc \check {c }}$ \\
\hline [2] & dostanete $0 \mathrm{Kc \check {c }}$ & nebo & dostanete $2 \mathrm{Kc \check {c }}$ \\
\hline [3] & dostanete $0 \mathrm{Kc \check {c }}$ & nebo & dostanete $4 \mathrm{~K} \check{\mathrm{c}}$ \\
\hline [4] & dostanete $0 \mathrm{Kc \check {c }}$ & nebo & dostanete 6 Kč \\
\hline [5] & dostanete $0 \mathrm{Kc \check {c }}$ & nebo & dostanete $8 \mathrm{Kc \check {C }}$ \\
\hline [6] & dostanete $0 \mathrm{Kc \check {c }}$ & nebo & dostanete $10 \mathrm{Kc \check {c }}$ \\
\hline [7] & dostanete $0 \mathrm{Kc \check {c }}$ & nebo & dostanete $12 \mathrm{Kc \check {c }}$ \\
\hline [8] & dostanete $0 \mathrm{Kc \check {c }}$ & nebo & dostanete $14 \mathrm{Kc \check { }}$ \\
\hline [9] & dostanete $0 \mathrm{Kc \check {c }}$ & nebo & dostanete $16 \mathrm{Kc \check { }}$ \\
\hline [10] & dostanete 0 Kč & nebo & dostanete $18 \mathrm{Kc \check {c }}$ \\
\hline [11] & dostanete $0 \mathrm{Kc \check {c }}$ & nebo & dostanete $20 \mathrm{Kc \check {c }}$ \\
\hline [12] & dostanete $0 \mathrm{Kc \check {c }}$ & nebo & dostanete $22 \mathrm{Kc \check {c }}$ \\
\hline [13] & dostanete $0 \mathrm{Kc \check {c }}$ & nebo & dostanete $24 \mathrm{Kc \check {c }}$ \\
\hline [14] & dostanete $0 \mathrm{Kc \check {c }}$ & nebo & dostanete $26 \mathrm{Kc \check { }}$ \\
\hline [15] & dostanete $0 \mathrm{Kc \check {c }}$ & nebo & dostanete $28 \mathrm{Kc \check {c }}$ \\
\hline [16] & dostanete $0 \mathrm{Kc \check { }}$ & nebo & dostanete 30 Kč \\
\hline [17] & dostanete $0 \mathrm{Kc \check {c }}$ & nebo & dostanete $32 \mathrm{Kc \check {c }}$ \\
\hline [18] & dostanete $0 \mathrm{Kc \check {c }}$ & nebo & dostanete $34 \mathrm{Kc \check {c }}$ \\
\hline [19] & dostanete $0 \mathrm{Kč}$ & nebo & dostanete 36 Kč \\
\hline [20] & dostanete $0 \mathrm{Kc \check {c }}$ & nebo & dostanete $38 \mathrm{Kc \check {c }}$ \\
\hline
\end{tabular}

Figure A.5

Instructions - screen 3

Now let's look at the example you have before you. For question 1, you have to find out which number under the options A to E is wood [" drevo" in Czech]. In the key above, you can find that the correct answer is B: 6393. So for question 1, you will choose the circle below B on the right side of your screen.

Your goal is to answer as many questions as possible within 5 minutes. When you answer all the questions on a given page, you can go to the next page using the "Next Set" ["další sada" in Czech] button. The remaining time is displayed in the box at the bottom right side of your screen.

And now the most important thing: your reward in this test depends on the number of correct answers. You will receive $1 \mathrm{CZK}$ for each correct answer. So your reward will be equal to the "number of correct answers" in CZK. However, if you assign the wrong number to a given word in more than $50 \%$ of cases, you will not receive any reward from this experiment.

Is everything clear? Leave time for questions and answer in private. 


\begin{tabular}{|c|c|c|c|}
\hline & Možnost A & nebo & Možnost B \\
\hline $\begin{array}{l}\text { Doba } \\
\text { čekáni }\end{array}$ & 0 minut & nebo & 60 minut \\
\hline & & & Pĩi čekáni mưžete čist Magazin M \\
\hline [1] & dostanete $0 \mathrm{Kč}$ & nebo & dostanete $0 \mathrm{Kc \check { }}$ \\
\hline [2] & dostanete $0 \mathrm{Kc \check {c }}$ & nebo & dostanete $2 \mathrm{Kc \check { }}$ \\
\hline [3] & dostanete $0 \mathrm{Kc \check {c }}$ & nebo & 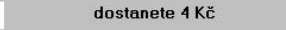 \\
\hline [4] & dostanete 0 Kč & nebo & dostanete 6 Kč \\
\hline [5] & dostanete $0 \mathrm{Kc \check {c }}$ & nebo & dostanete $8 \mathrm{Kc \check {c }}$ \\
\hline [6] & dostanete $0 \mathrm{Kc \check {c }}$ & nebo & dostanete $10 \mathrm{Kc \check {c }}$ \\
\hline [7] & dostanete $0 \mathrm{~K} \check{\mathrm{c}}$ & nebo & dostanete $12 \mathrm{Kc \check {c }}$ \\
\hline [8] & dostanete $0 \mathrm{Kč}$ & nebo & dostanete $14 \mathrm{Kc \check {c }}$ \\
\hline [9] & dostanete 0 Kč & nebo & dostanete $16 \mathrm{Kc \check {c }}$ \\
\hline [10] & dostanete $0 \mathrm{Kc \check {c }}$ & nebo & dostanete $18 \mathrm{Kc \check {c }}$ \\
\hline [11] & dostanete $0 \mathrm{Kc \check {c }}$ & nebo & dostanete $20 \mathrm{Kc \check {c }}$ \\
\hline [12] & dostanete 0 Kč & nebo & dostanete $22 \mathrm{Kc \check {c }}$ \\
\hline [13] & dostanete $0 \mathrm{Kc \check {c }}$ & nebo & dostanete $24 \mathrm{Kc \check {C }}$ \\
\hline [14] & dostanete $0 \mathrm{Kc \check { }}$ & nebo & dostanete 26 Kč \\
\hline [15] & dostanete $0 \mathrm{Kc \check {c }}$ & nebo & dostanete $28 \mathrm{Kc \check {c }}$ \\
\hline [16] & dostanete $0 \mathrm{Kc \check {c }}$ & nebo & dostanete $30 \mathrm{Kc \check {c }}$ \\
\hline [17] & dostanete $0 \mathrm{Kc \check { }}$ & nebo & dostanete $32 \mathrm{Kc \check {c }}$ \\
\hline [18] & dostanete $0 \mathrm{Kc \check {C }}$ & nebo & dostanete $34 \mathrm{Kc \check {c }}$ \\
\hline [19] & dostanete $0 \mathrm{Kc \check {c }}$ & nebo & dostanete 36 Kč \\
\hline [20] & dostanete $0 \mathrm{Kc}$ & nebo & dostanete 38 Kč \\
\hline
\end{tabular}

Figure A.6

Instructions - screen 4 


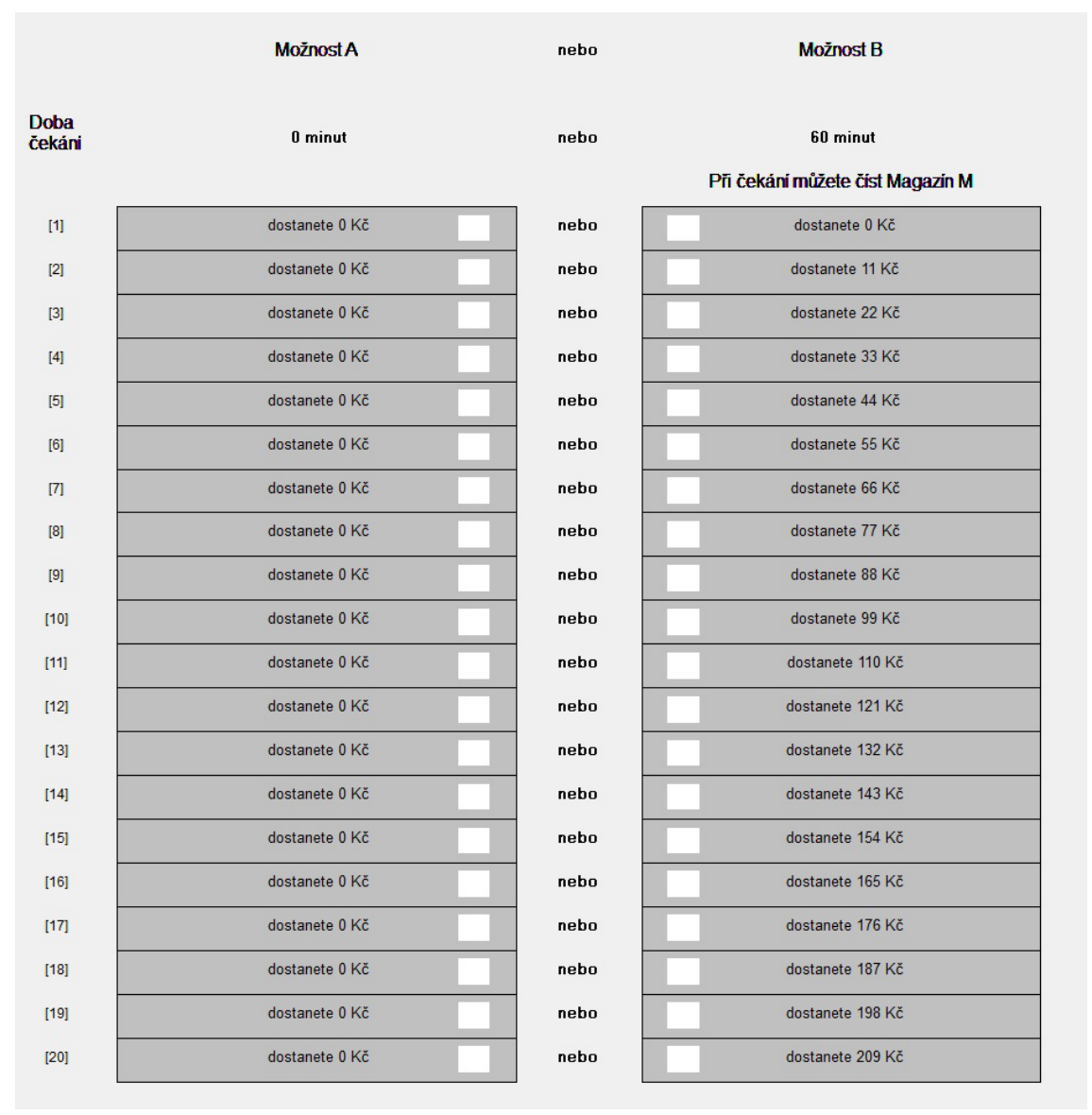

Figure A.7

A screenshot of the MPL used in the experiment. 


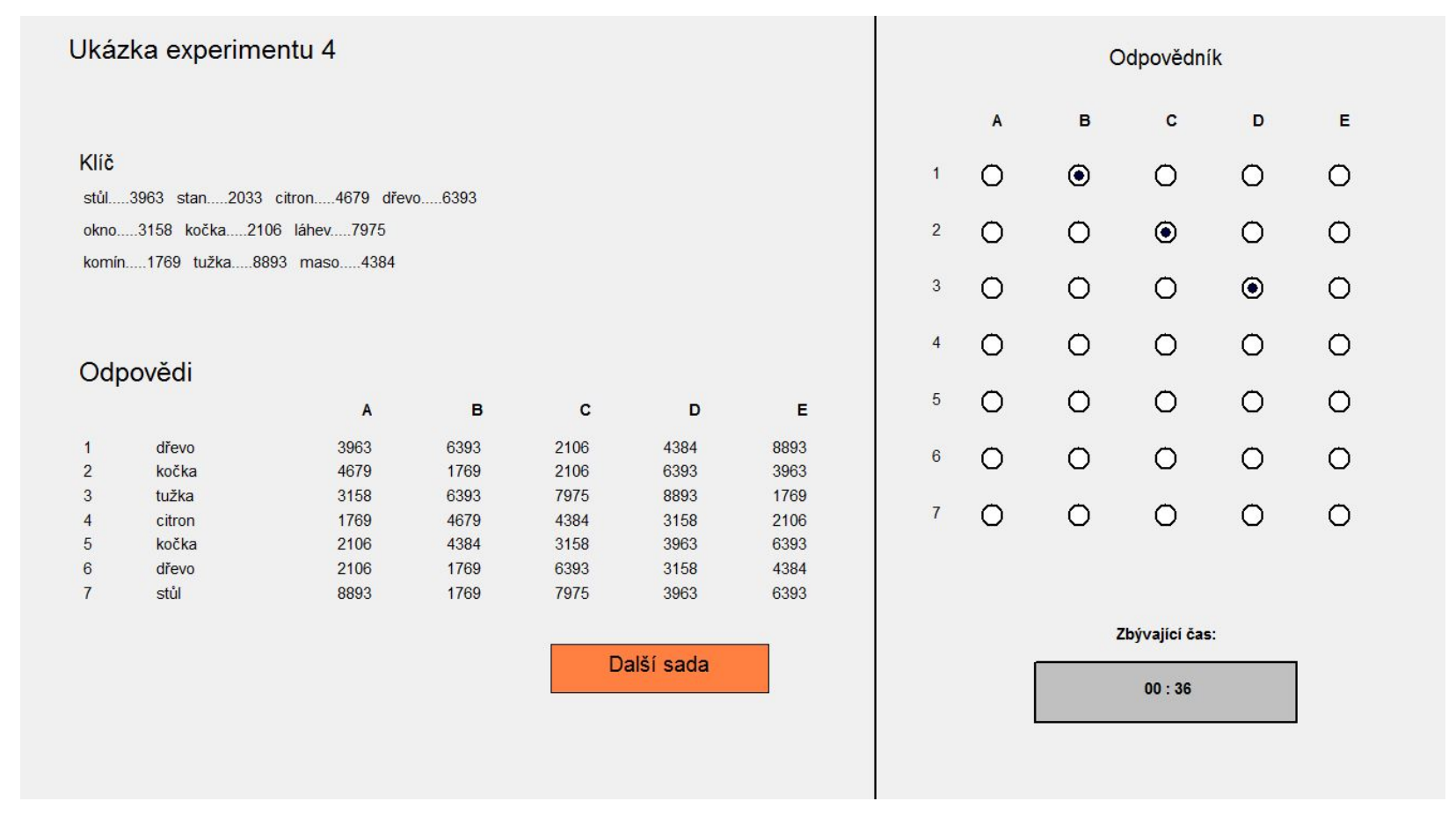

Figure A.8

Screen of the coding speed test presented during the reading of the instructions. In the upper left corner, there is the key containing 10 words with codes. Below that there are the questions (1-7). The right side of the screen displays the answer sheet. 


\section{MUNI Econ Working Paper Series (since 2018)}

2021-01 Krčál, O., Peer, S., Staněk, R. (2021). Can time-inconsistent preferences explain hypothetical biases?. MUNI ECON Working Paper n. 2021-01. Brno: Masaryk University. https://doi.org/10.5817/WP_MUNI_ECON_2021-01

2020-04 Pelligra, V., Reggiani, T., Zizzo, D.J. 2020. Responding to (Un)Reasonable Requests by an Authority. MUNI ECON Working Paper n. 2020-04. Brno: Masaryk University. https://doi.org/10.5817/WP_MUNI_ECON_2020-04

2020-03 de Pedraza, P., Guzi, M., Tijdens, K. 2020. Life Dissatisfaction and Anxiety in COVID-19 pandemic. MUNI ECON Working Paper n. 2020-03. Brno: Masaryk University. https://doi.org/10.5817/WP_MUNI_ECON_2020-03

2020-02 de Pedraza, P., Guzi, M., Tijdens, K. 2020. Life Satisfaction of Employees, Labour Market Tightness and Matching Efficiency. MUNI ECON Working Paper n. 2020-02. Brno: Masaryk University. https://doi.org/10.5817/WP_MUNI_ECON_2020-02

2020-01 Fišar, M., Reggiani, T., Sabatini, F., Špalek, J. 2020. a. MUNI ECON Working Paper n. 2020-01. Brno: Masaryk University. https://doi.org/10.5817/WP_MUNI_ECON_2020-01

2019-08 Fišar, M., Krčál, O., Špalek, J., Staněk, R., Tremewan, J. 2019. A Competitive Audit Selection Mechanism with Incomplete Information. MUNI ECON Working Paper n. 2019-08. Brno: Masaryk University. https://doi.org/10.5817/WP_MUNI_ECON_2019-08

2019-07 Guzi, M., Huber, P., Mikula, M. 2019. Old sins cast long shadows: The Long-term impact of the resettlement of the Sudetenland on residential migration. MUNI ECON Working Paper n. 2019-07. Brno: Masaryk University. https://doi.org/10.5817/WP_MUNI_ECON_2019-07

2019-06 Mikula, M., Montag, J. 2019. Does homeownership hinder labor market activity? Evidence from housing privatization and restitution in Brno. MUNI ECON Working Paper n. 2019-06. Brno: Masaryk University. https://doi.org/10.5817/WP_MUNI_ECON_2019-06

2019-05 Krčal, O., Staněk, R., Slanicay, M. 2019. Made for the job or by the job? A lab-in-the-field experiment with firefighters. MUNI ECON Working Paper n. 2019-05. Brno: Masaryk University. https://doi.org/10.5817/WP_MUNI_ECON_2019-05

2019-04 Bruni, L., Pelligra, V., Reggiani, T., Rizzolli, M. 2019. The Pied Piper: Prizes, Incentives, and Motivation Crowding-in. MUNI ECON Working Paper n. 2019-04. Brno: Masaryk University. https://doi.org/10.5817/WP_MUNI_ECON_2019-04

2019-03 Krčál, O., Staněk, R., Karlínová, B., Peer, S. 2019. Real consequences matters: why hypothetical biases in the valuation of time persist even in controlled lab experiments. MUNI ECON Working Paper n. 2019-03. Brno: Masaryk University. https://doi.org/10.5817/WP_MUNI_ECON_2019-03

2019-02 Corazzini, L., Cotton, C., Reggiani, T., 2019. Delegation And Coordination With Multiple Threshold Public Goods: Experimental Evidence. MUNI ECON Working Paper n. 2019-02. Brno: Masaryk University. https://doi.org/10.5817/WP_MUNI_ECON_2019-02 
2019-01 Fišar, M., Krčál, O., Staněk, R., Špalek, J. 2019. The Effects of Staff-rotation in Public Administration on the Decision to Bribe or be Bribed. MUNI ECON Working Paper n. 2019-01. Brno: Masaryk University. https://doi.org/10.5817/WP_MUNI_ECON_2019-01

2018-02 Guzi, M., Kahanec, M. 2018. Income Inequality and the Size of Government: A Causal Analysis. MUNI ECON Working Paper n. 2018-02. Brno: Masaryk University. https://doi.org/10.5817/WP_MUNI_ECON_2018-02

2018-01 Geraci, A., Nardotto, M., Reggiani, T., Sabatini, F. 2018. Broadband Internet and Social Capital. MUNI ECON Working Paper n. 2018-01. Brno: Masaryk University. https://doi.org/10.5817/WP_MUNI_ECON_2018-01

ISSN electronic edition 2571-130X

MUNI ECON Working Paper Series is indexed in RePEc:

https://ideas.repec.org/s/mub/wpaper.html 